\title{
Post-Operative Complications in Radical Cystectomy: Can the Kind of Urinary Diversion, The Performance Status, Presence of Preoperative Hydronephrosis or Tumor Extension Predict the Likelihood of Post-Operative Complications?
}

ISSN: 2578-0093

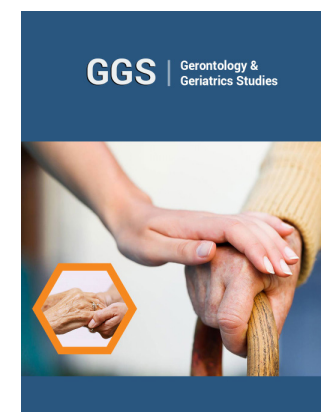

${ }^{*}$ Corresponding author: Fiorello N, Italy

Submission: 眥 April 24, 2019

Published: 紫May 15, 2019

Volume 4 - Issue 5

How to cite this article: Fiorello N, Jallous H, Porru D, Marchetti C, Giliberto GL, et al . Post-Operative Complications in Radical Cystectomy: Can the Kind of Urinary Diversion, The Performance Status, Presence of Preoperative Hydronephrosis or Tumor Extension Predict the Likelihood of Post-Operative Complications?. Gerontol \& Geriatric stud.4(5). GGS.000596.2019. DOI: 10.31031/GGS.2019.04.000597

Copyright@ Fiorello N, This article is distributed under the terms of the Creative Commons Attribution 4.0 International License, which permits unrestricted use and redistribution provided that the original author and source are credited.
Fiorello N*, Jallous H, Porru D, Marchetti C, Giliberto GL, Regina C, Ringressi A, Cebrelli T and Simeone C

Italy

\section{Introduction}

Radical cystectomy (RC) is recommended for T2-4 N0 M0 bladder cancer and high-risk non-muscle invasive bladder cancer [1]. Before planning the surgery it's extremely important to select the patients to choose the urinary diversion, to evaluate the performance status with a standardized score and any specialist assessments if there are serious comorbidities [2]. Despite improvements in the surgical technique and in the approach, the procedure remains associated with significant postoperative morbidity with high rates of complications [3] Standard RC consists of the removal of the bladder, prostate, seminal vesicles, distal ureters, and regional lymph nodes in men, and the bladder, urethra, adjacent vagina, uterus, distal ureters, and regional lymph nodes in women [4]. In our study we examined post-operative complications, classified with Clavien-Dindo score, and we looked for possible correlations between type of urinary derivation, preoperative hydronephrosis (related to the disease or to a previous Transurethral Resection of Bladder [TURB]), performance status and tumor extension.

\section{Materials and Methods}

In our study we have enrolled 213 patients, 171 men and 42 women, and we have evaluated the anatomical features, the comorbidities, clinical extension of tumor to plane the surgery. The average age is 74, 52 years. For every patient regional or extended lymphadenectomy was performed. The kinds of urinary diversion are been Ureterocutaneostomy (UCS), Ureteroileocutaneostomy (UICS, with Wallace I/II or Bricker technique), or neobladder. The mean duration of surgery is 4.21 hours. In most cases the lymphadenectomy performed concerns the iliac-obturator and external iliac lymph nodes. In some cases the lymphadenectomy has been extended to the retrocrural lymph nodes. The main urinary performed has been the UCS and UICS. The ileal orthotopic neobladder has been reserved for selected cases, because great experience of the surgeon is required, and there is a high risk of complications. Performance status has been evaluated with Charlson score, in the Table 1 are showed the median, the minimum and maximum value. 75 patients had preoperative hydronephrosis. In most cases it is due to the extension of the tumor at bladder trigone. In 7 patients hydronephrosis was due to previous TURB performed for tumors near the ureteral hosts. In some cases the patients were affected by simultaneous primary tumors.

The simultaneous prostatic tumor has been treated with standard cystectomy. The other tumors, that included in 4 cases the ureters and 3 cases the kidney (molateral parenchymal tumors), was treated with extended surgery, with simultaneous nephrouretectomy. In one case the patient was affected by digiunal tumor. The digiunal resection was performed in multidisciplinary equip. The final histological results have showed 37 tumors with local 
extension pT4, 71 tumors with local extension pT3, 50 tumors with local extension pT2, 47 tumors with non-muscle invasive tumors (pT1). 8 patients didn't have tumor (pT0). In 33 patients there were regional lymph node metastasis, (pN1), in 2 patients there were an extra regional lymph node metastasis (pN2). 2 patients had single metastasis before surgery (both lung metastasis) (Table 1-3).

Table 1: The shows the median value of the performance status for all patients, classified with Charlson score; the minum value is 4 and the maximum value is 12 . The patients with hydronephrosis before cystectomy are 75 ; in some cases, associated primitive tumors are associated. $\mathrm{T}$ (tumor extension), $\mathrm{N}$ and $\mathrm{M}$ for lymph node and systemic metastases.

\begin{tabular}{|c|c|c|c|c|c|}
\hline Charlson Score & Hydronephrosis & Associated Tumors & $\mathrm{T}$ (local extension) & $\mathbf{N}$ & M \\
\hline $\begin{array}{l}\text { Median (6) } \\
\text { imum value (4) Maximum } \\
\text { value (12) }\end{array}$ & 75 & $\begin{array}{l}\text { Prostatic cancer (33) } \\
\text { Digiunal Cancer (1) } \\
\text { Ureteral Cancer (4) } \\
\text { Kidney Cancer (3) } \\
\text { Prostatic cancer-33 }\end{array}$ & $\begin{array}{l}\text { pT0 (8) } \\
\text { pT1 (47) } \\
\text { pT2 (50) } \\
\text { pT3 (71) } \\
\text { pT4 (37) }\end{array}$ & $\begin{array}{l}\text { N1 (33) } \\
\text { N2 (8) }\end{array}$ & $M+(2)$ \\
\hline
\end{tabular}

Table 2: The shows the total number of patients, the average age of 74.52years old, the level of linfoadenectomy performed, that in most cases it concerns the iliac-obturator and external iliac lymph nodes, the kind of urinary diversion and the average duration of surgery.

\begin{tabular}{|c|c|c|c|c|}
\hline $\mathbf{N}^{\circ}$ patients & Age (years) & Level of linfoadenectomy & Urinary Diversion & Duration (hours) \\
\hline & & Iliac-obturator (90) & Ureterocutaneostomy (96) & Ureteroileocutaneostomy (89) \\
213 & \multirow{2}{*}{74,52} & External iliac (71) & Neobladder (28) & 4,21 \\
& & Common iliac (34) & & \\
\hline
\end{tabular}

Table 3: The shows the istology for every tumor.

\begin{tabular}{|c|c|c|c|c|c|}
\hline \multicolumn{2}{|c|}{ Hystology } \\
\hline $\begin{array}{c}\text { TCC High grade } \\
(176)\end{array}$ & TCC low grade (14) & Multifocal CIS (6) & Adenocarcinoma (5) & $\begin{array}{c}\text { Pleomorphic Sarco- } \\
\text { ma (2) }\end{array}$ & \begin{tabular}{c} 
Indifferentiated carcinoma (1) \\
\hline
\end{tabular}
\end{tabular}

\section{Result}

We have analyzed every kind of peri-postoperative complication, classified according Clavien-Dindo system. We have observed 59 patients that had complications, of which 39 Aneamia, 11 enteral sub-ileus, 2 acute renal insufficiency (ARI) for ureteral obstruction, 4 surgical wound infections, 1 urosepsis for skin fistula, 2 retroperitoneal bleeding. For every kind of complication the therapeutic approach is been different. The standard treatment for Aneamia was blood transfusion, to obtain a clinical course safe and stable. Subileus has been managed with medical therapy (antibiotics and intravenous hydration) or, in 3 patients, with nasogastric tube placement. The patients with obstructive ARI needed a percutaneous nephrostomy. Surgical wound infections have been managed with medication and antibiotics therapy.

In one case surgery provoked skin fistula with urosepsis. This patient was treated with daily medication and antibiotics therapy for 3 weeks, until resolution of complication. 2 patients had an important retroperitoneal bleeding, not manageable with blood transfusion or selective embolization. They needed a surgical treatment (re-laparotomy) with following resolution of complication (Table $4 \& 5$ ). We have looked for any correlations with the performance status of the patients, classified according Charlson score, but the rate of complications wasn't directly related to comorbidity of patients. The most complex kind of urinary diversion is the neobladder, but it needs carefully selection of patients and great experience of surgeon. Despite neobladder is related to high rate of complications in this study the surgical complexity wasn't directly related to rate of compliance. Preoperative hydronephrosis was related in most cases to local extension of tumor. In 7 patients hydronephrosis was provoked by previous TURB of tumors that involved the ureteral ostium. We haven't found relations between preoperative hydronephrosis and post-operative complications. Local extension of tumor certainly makes the intervention more complex, but we haven't found direct relation between local extension and post-operative complications (Table 4).

\section{Discussion}

In literature post-operative complications of cystectomy are well described. Immediate postoperative complications and 90day mortality in radical cystectomy in high-risk patients remain significant [5]. The indication to the surgery must be well studied and the patients must be well selected to choose the appropriate 
type of urinary diversion. Complications can be easily managed but in some cases they can be very serious and needed continuous monitoring of patients or invasive treatment. In literature there aren't studies that demonstrate clear correlations to predict postoperative complications (Table 5).

Table 4. The shows all periperative complications and the medical or surgical treatment.

\begin{tabular}{|c|c|c|c|c|c|c|}
\hline & Aneamia & Sub-ileus & ARI (obstructive) & $\begin{array}{c}\text { Surgical wound } \\
\text { infection }\end{array}$ & $\begin{array}{c}\text { Urosepsis for } \\
\text { skin fistula }\end{array}$ & $\begin{array}{c}\text { Retroperitoneal bleed- } \\
\text { ing }\end{array}$ \\
\hline $\mathrm{N}^{\circ}$ patients & 39 & 11 & 2 & 4 & 1 & 2 \\
\hline Clavien-Dindo & 2 & 2-Jan & 2 & 1 & 1 & 3 \\
\hline Therapy & $\begin{array}{c}\text { Blood transfu- } \\
\text { sion }\end{array}$ & $\begin{array}{c}\text { Nasogastric tube/ } \\
\text { Antibiotics }\end{array}$ & $\begin{array}{c}\text { Percutaneous ne- } \\
\text { phrostomy }\end{array}$ & $\begin{array}{c}\text { Medication and } \\
\text { antibiotics }\end{array}$ & $\begin{array}{c}\text { Medication and } \\
\text { antibiotics }\end{array}$ & Re-laparotomy \\
\hline
\end{tabular}

Table 5. The number of patients with complications on the total number of patients for every kind of urinary diversion. It also shows the rate of complications for every kind of urinary diversion.

\begin{tabular}{|c|c|}
\hline & $\mathbf{N}^{\circ}$ patients with complications/ total number of patients with the type of urinary diversion \\
\hline Ureterocutaneostomy & $49 / 96(50,1 \%)$ \\
\hline Ureteroileocutaneostomy & $14 / 89(15.7 \%)$ \\
\hline Neobladder & $7 / 28(25 \%)$ \\
\hline
\end{tabular}

\section{Conclusion}

The radical cystectomy is an invasive treatment reserved to muscle-invasive tumors of bladder and for patients who do not have excessive comorbidity. The further selection of patients is necessary to choose the kind of urinary diversion and it needs great experience of surgeon. Despite the improvement of surgical skills of urologists the radical cystectomy remains an invasive treatment with a high rate of complications, which must be managed in the most appropriate way. In our study, according to literature, it wasn't possible found a way to predict the rate of post- operative complications.

\section{References}

1. Shabsigh A, Korets R, Vora KC (2008) Defining early morbidity of radical cystectomy for patients with bladder cancer using a standardized reporting methodology. Eur Urol 55(1): 164-174.
2. Witjes JA, Compérat E, Cowan NC, De Santis M, Gakis G, et al. (2014) EAU guidelines on muscle-invasive and metastatic bladder cancer: summary of the 2013 guidelines. European Association of Urology. Eur Urol 65(4):778-792.

3. Cookson MS, Chang SS, Wells N, Parekh DJ, Smith JA (2003) Complications of radical cystectomy for nonmuscle invasive disease: comparison with muscle invasive disease. J Urol 169(1):101-104.

4. Alfred WJ, Lebret T, Compérat EM, Cowan NC, De Santis M, et al. (2017) Updated 2016 EAU guidelines on muscle-invasive and metastatic bladder cancer. Eur Urol 71(3): 462-475.

5. Pavone C, Candela L, Fontana D, Simonato A (2018) Postoperative complications and 90-day mortality in radical cystectomy in high-risk patients: A monocentric retrospective observational study. Urologia 85(3): 111-117. 